九州大学学術情報リポジトリ

Kyushu University Institutional Repository

\title{
Intermolecular Interaction and a Concentration- Quenching Mechanism of Phosphorescent Ir(III) Complexes in a Solid Film
}

Kawamura, Yuichiro

CREST Program, Japan Science and Technology Agency (JST)

Brooks, Jason

Universal Display Corporation (UDC)

Brown, Julie J.

Universal Display Corporation (UDC)

Sasabe, Hiroyuki

Department of Photonics Materials Science, Chitose Institute of Science and Technology (CIST)

他

http://hdl. handle. net/2324/19454

出版情報: Physical Review B. 96 (1)，2006-01-12. The American Physical Society バージョン :

権利関係: The American Physical Society 


\title{
Intermolecular Interaction and a Concentration-Quenching Mechanism of Phosphorescent Ir(III) Complexes in a Solid Film
}

\author{
Yuichiro Kawamura, ${ }^{1}$ Jason Brooks, ${ }^{2}$ Julie J. Brown, ${ }^{2}$ Hiroyuki Sasabe, ${ }^{3}$ and Chihaya Adachi ${ }^{1,3,4, *}$ \\ ${ }^{1}$ CREST program, Japan Science and Technology Agency (JST), 1-32-12 Higashi, Shibuya, Tokyo 150-0011, Japan \\ ${ }^{2}$ Universal Display Corporation (UDC), 375 Phillips Boulevard, Ewing, New Jersey 08618, USA \\ ${ }^{3}$ Department of Photonics Materials Science, Chitose Institute of Science \& Technology (CIST), 758-65 Bibi, Chitose, \\ Hokkaido 066-8655, Japan \\ ${ }^{4}$ Center for Future Chemistry, Kyushu University, 744 Motooka, Nishi, Fukuoka 819-0395, Japan
}

(Received 7 August 2005; published 12 January 2006)

\begin{abstract}
Solid-state self-quenching processes of highly efficient Ir(III) phosphorescent emitters are investigated by the measurement of thin film photoluminescence quantum efficiency and transient lifetime as a function of doping concentration in a host matrix. The radiative decay rate constant is found to be independent from the average distance between dopant molecules $(R)$, and the concentration-quenching rate constant is shown to be dependent on $R^{-6}$. The quenching dependence on $R$ strongly suggests that luminescent concentration quenching in a phosphorescent $\operatorname{Ir}(\mathrm{III})$ complex:host film is controlled by dipole-dipole deactivating interactions as described by the Förster energy transfer model.
\end{abstract}

DOI: 10.1103/PhysRevLett.96.017404

PACS numbers: 78.66.Qn, 78.55.Kz

The photophysical properties of organic phosphors in a molecularly doped thin film, notably the photoluminescence (PL) quantum efficiency $\left(\eta_{\mathrm{PL}}\right)$, can provide important information on how to optimize the external electroluminescence (EL) efficiency $\left(\eta_{\mathrm{EL}}\right)$ of organic light emitting diodes. In previous studies, we reported that the green phosphorescent complex fac-tris(2-phenylpyridinato)iridium(III) $\left[\operatorname{Ir}(\mathrm{ppy})_{3}\right]$ has an $\eta_{\mathrm{PL}}$ of $97 \% \pm$ $2 \%$ when doped in the wide energy gap host, 4, 4'-bis( $N$-carbazolyl)-2, 2'-biphenyl (CBP) [1]. The high PL quantum yield corresponds well to the high efficiency devices reported for $\operatorname{Ir}(\mathrm{ppy})_{3}$ that are believed to be close to the theoretical device efficiency limit due to out-coupling losses $\left(\eta_{\mathrm{EL}} \sim 19 \%\right)$ [2,3]. By using a suitable high triplet energy host, such as $m$-bis( $N$-carbazolyl)benzene (mCP), it was shown that excitons could be confined on the blue Ir(III) complex, bis[(4, 6-difluorophenyl)pyridinato $\left.-\mathrm{N}, \mathrm{C}^{2}\right]$ (picolinato) iridium(III) [FIrpic] [4], also providing nearly 100\% PL efficiency [1]. These measurements were well supported by the lack of temperature dependence on phosphorescence intensity, and no delayed transient component due to back energy transfer to the host was observed [5-7].

It is well known that many fluorescent materials are severely quenched as neat films due to significant overlap of absorption and emission. While phosphorescent $\operatorname{Ir}(\mathrm{III})$ complexes emitting from mixed ${ }^{3}$ MLCT (metal to ligand charge transfer triplet state) $/ \pi-\pi^{*}$ transitions tend to be less absorptive in the region of emission, they are also known to suffer from significant PL quenching at increased dopant concentrations. Concentration quenching in neat films of both monomeric [1] and dendrimeric [8] phosphorescent materials has been reported, but thus far the nature of the quenching mechanism has not been clarified. Herein, we studied the solid-state PL concentration depen- dence of three principal phosphorescent Ir(III) complexes in order to elucidate the mechanism of concentration quenching and the intermolecular interactions that occur between the ground and excited states (i.e., donor-acceptor spectral overlap). Both $\eta_{\mathrm{PL}}$ and transient PL lifetime $\left(\tau_{\mathrm{PL}}\right)$ are measured and described as a function of the average distance between the Ir(III) complexes. The intermolecular distance dependency on PL is discussed in terms of the radiative rate constant $\left(k_{\mathrm{ph}}\right)$ and the concentrationquenching rate constant $\left(k_{\mathrm{CQ}}\right)$ based on the dipole-dipole interaction theory described by Förster energy transfer [9].

Three $\operatorname{Ir}(\mathrm{III})$ dopants were evaluated; $\operatorname{Ir}(\mathrm{ppy})_{3}$ for green, bis[2-(2'-benzothienyl)pyridinato- $\left.\mathrm{N}, \mathrm{C}^{3^{\prime}}\right]-$ (acetylacetonato)iridium(III) [Btp $\left.{ }_{2} \operatorname{Ir}(\mathrm{acac})\right]$ [10] for red, and FIrpic [4] for blue. Two organic materials were used as hosts, CBP for $\operatorname{Ir}(\mathrm{ppy})_{3}$ and $\mathrm{Btp}_{2} \operatorname{Ir}(\mathrm{acac})$, and $\mathrm{mCP}$ [11] for FIrpic. These hosts were chosen because they are known to effectively confine the triplet excitons on the guest phosphors [5]. The $\operatorname{Ir}(\mathrm{III})$ complex: host composite films were fabricated using conventional thermal vacuum codeposition (at $2 \times 10^{-3} \mathrm{~Pa}$ ) on precleaned quartz substrates for measurement of the absolute $\eta_{\mathrm{PL}}$ and on silicon substrates for measurement of the $\tau_{\mathrm{PL}}$. The films had a thickness of $100 \mathrm{~nm}$ and doping concentrations ranging from 1.2 to $100 \mathrm{~mol} \%$ (2 to $100 \mathrm{wt} \%$ ). The $\tau_{\mathrm{PL}}$ was measured using a streak camera (C4334, Hamamatsu Photonics Co.) with an $\mathrm{N}_{2}$ gas laser (MNL 200, Laser Technik Berlin, $\lambda=337 \mathrm{~nm}$, pulse width $\approx 500 \mathrm{ps}$, repetition rate $=20 \mathrm{~Hz}$ ) as the excitation source. The measurements were done under low pressure $\left(\sim 1 \times 10^{-1} \mathrm{~Pa}\right)$ in a cryostat. The $\eta_{\mathrm{PL}}$ of the films was measured under $\mathrm{N}_{2}$ flow using an integrating sphere based on our previous paper [12]. The PL was measured using a multichannel spectrophotometer (PMA-11 C7473, Hamamatsu Photonics Co.), and the UV-visible absorption 
spectra was measured by a UV-VIS-IR spectrophotometer (SHIMADZU UV-3100).

The concentration quenching of the phosphors is expressed by the rate constant, $k_{\mathrm{CQ}}$, determined from the equation for $\eta_{\mathrm{PL}}$ :

$$
\eta_{\mathrm{PL}}=\eta_{\mathrm{et}} \eta_{\mathrm{isc}} \frac{k_{\mathrm{ph}}}{k_{\mathrm{ph}}+k_{\mathrm{nr}}+k_{\mathrm{CQ}}},
$$

where $\eta_{\mathrm{et}}$ is the efficiency of the energy transfer from a host to a dopant, $\eta_{\text {isc }}$ is the intersystem crossing efficiency, $k_{\mathrm{ph}}$ is the rate of radiative decay from the excited dopant, and $k_{\mathrm{nr}}$ is the rate of nonradiative decay. Energy transfer from the excited singlet state of the host to the dopant occurs quantitatively via Förster energy transfer. Since the energy transfer rate from the host to the guest is high [1] $\left(k_{\mathrm{et}} \approx 10^{12} \mathrm{~s}^{-1}\right)$ and no fluorescence is observed from the host at the doping concentrations used in this experiment, the intersystem crossing efficiency of the dopant, $\eta_{\text {isc }}$, must be nearly $100 \%$ [13].

The concentration dependence on the emission lifetime, $\tau_{\mathrm{PL}}$, was also measured for the $\operatorname{Ir}(\mathrm{III})$ complex:host films. The $\tau_{\mathrm{PL}}$ was obtained by fitting to a single exponential decay model as the first approximation. As shown in Fig. 1, the units for the horizontal axis were converted from mol\% to the average distance between two dopants $(R)$ using the following equation: $R=[$ (molecular density in film $) \times$ mol $\%$ of the dopant in a film $]^{-1 / 3}$. It was found that both $\eta_{\mathrm{PL}}$ and $\tau_{\mathrm{PL}}$ exhibited similar dependences on the average distance between the $\operatorname{Ir}(\mathrm{ppy})_{3}$ molecules [inset of Fig. 1(a)]. The $k_{\mathrm{ph}}$, calculated from $\eta_{\mathrm{PL}} / \tau_{\mathrm{PL}}$ where $\tau_{\mathrm{PL}}$ is defined as $1 /\left(k_{\mathrm{ph}}+k_{\mathrm{nr}}+k_{\mathrm{CQ}}\right)$, was $8.0 \times 10^{5} \mathrm{~s}^{-1}$, and showed no significant change as a function of $R$ [Fig. 1(a)]. The $k_{\text {ph }}$ values for FIrpic:mCP [Fig. 1(b)] and $\mathrm{Btp}_{2} \operatorname{Ir}(\mathrm{acac}): \mathrm{CBP}$ [Fig. 1(c)] were also found to be independent of $R$, and were measured to be $7.5 \times 10^{5} \mathrm{~s}^{-1}$ and $0.94 \times 10^{5} \mathrm{~s}^{-1}$, respectively. This suggests that the radiative decay characteristics of the ${ }^{3}$ MLCT transitions are insensitive to $R$.

On the other hand, $k_{\mathrm{CQ}}$ values were found to be highly dependent on $R$. As shown in Fig. 1, the value of $k_{\mathrm{CQ}}$ is negligible when $R>2 \mathrm{~nm}$, and increases significantly when $R<2 \mathrm{~nm}$. It is noted that the $k_{\mathrm{CQ}}$ values for $\mathrm{Btp}_{2} \operatorname{Ir}(\mathrm{acac})$ were calculated by assuming an intrinsic nonradiative decay rate of $k_{\mathrm{nr}}=0.91 \times 10^{5} \mathrm{~s}^{-1}$, since the $\mathrm{Btp}_{2} \operatorname{Ir}(\mathrm{acac}): \mathrm{CBP}$ film showed a maximum $\eta_{\mathrm{PL}}=51 \%$ at high dilution, suggesting that $k_{\mathrm{ph}} \approx k_{\mathrm{nr}}$ [14].

Figure 2 shows $k_{\mathrm{CQ}}$ vs $R$ for the three $\operatorname{Ir}(\mathrm{III})$ complex: host films plotted to a double logarithmic scale. From this it was found that the $k_{\mathrm{CQ}}$ values clearly showed dependence to $R^{-6}$ in each case, thereby indicating that the Förster dipole-dipole interaction controls the concentration quenching. Here, the rate constant for the Förster energy transfer [9] is given by the equation

$$
k=\frac{1}{\tau_{\mathrm{PL}}}\left(\frac{R_{0}}{R}\right)^{6},
$$

(a)

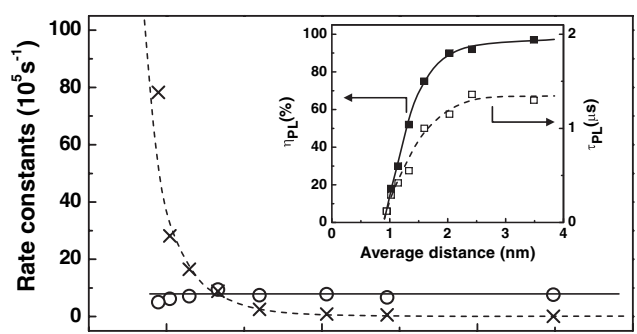

(b)

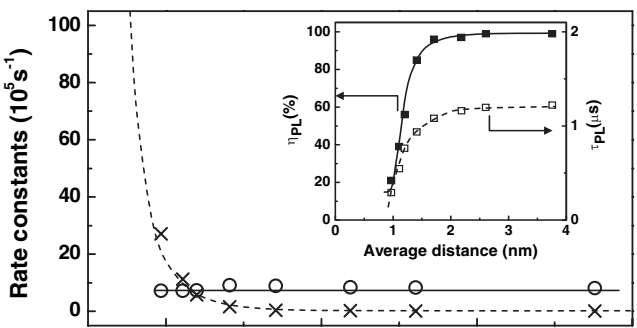

(c)

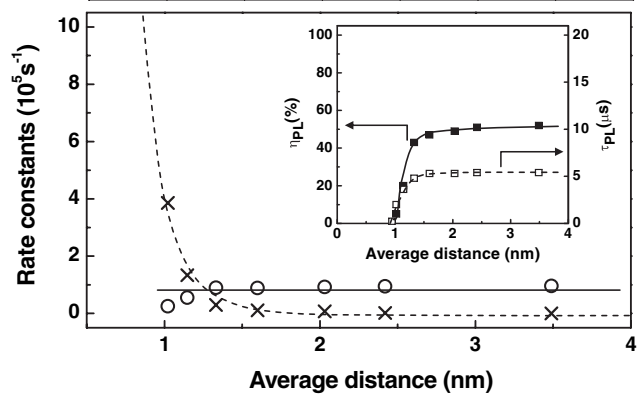

FIG. 1. Dependence of radiative (open circle) and concentration-quenching (cross-hair) rate constants, $k_{\mathrm{ph}}$ and $k_{\mathrm{CQ}}$, on average distance $(R)$ between two $\operatorname{Ir}(\mathrm{III})$ complexes for (a) $\operatorname{Ir}(\text { ppy })_{3}: \mathrm{CBP}$, (b) FIrpic:mCP, and (c) $\mathrm{Btp}_{2} \operatorname{Ir}(\mathrm{acac}): \mathrm{CBP}$. Insets show the $R$ dependence of PL quantum efficiency $\eta_{\mathrm{PL}}$ (filled squares) and emission lifetime $\tau_{\mathrm{PL}}$ (open squares).

where $\tau_{\mathrm{PL}}$ is the intrinsic radiative decay lifetime of the donor, $R$ is the distance between the donor and the acceptor, and $R_{0}$ is the critical distance for the concentration quenching (Förster radius). Using this model, theoretical plots shown as the dashed lines in Fig. 2 are found to fit well with the experimental values. The calculation for the $\operatorname{Ir}(\mathrm{ppy})_{3}$ : CBP film was done using the experimentally obtained value of $\tau_{\mathrm{PL}}=1.3 \mu \mathrm{s}$, and a fitting parameter of $R_{0}=1.4 \pm 0.1 \mathrm{~nm}$. Furthermore, excellent agreement between experimental values and theory was obtained for both FIrpic and $\operatorname{Btp}_{2} \operatorname{Ir}(\mathrm{acac}) ; \tau_{\mathrm{PL}}=1.2 \mu \mathrm{s}$ and $R_{0}=$ $1.4 \pm 0.1 \mathrm{~nm}$ for FIrpic and $\tau_{\mathrm{PL}}=5.4 \mu \mathrm{s}$ and $R_{0}=0.8 \pm$ $0.1 \mathrm{~nm}$ for $\mathrm{Btp}_{2} \operatorname{Ir}(\mathrm{acac})$. The small values for $R_{0}$ and the independence of $k_{\mathrm{ph}}$ on $R$ indicate that the distance requirements for intermolecular quenching interaction between the phosphors is significantly less when compared with that of the conventional fluorescent materials that typically have an $R_{0}=5-10 \mathrm{~nm}$ in an amorphous thin film.

Another expression for Förster energy transfer [9] is given by

$$
R_{0}=\sqrt[6]{\frac{9000 c^{4} \ln 10 \chi^{2} \eta_{\mathrm{PL}}}{128 \pi^{5} n^{4} N_{A}} \int f_{D}(\nu) \varepsilon_{A}(\nu) \frac{d \nu}{\nu^{4}}},
$$




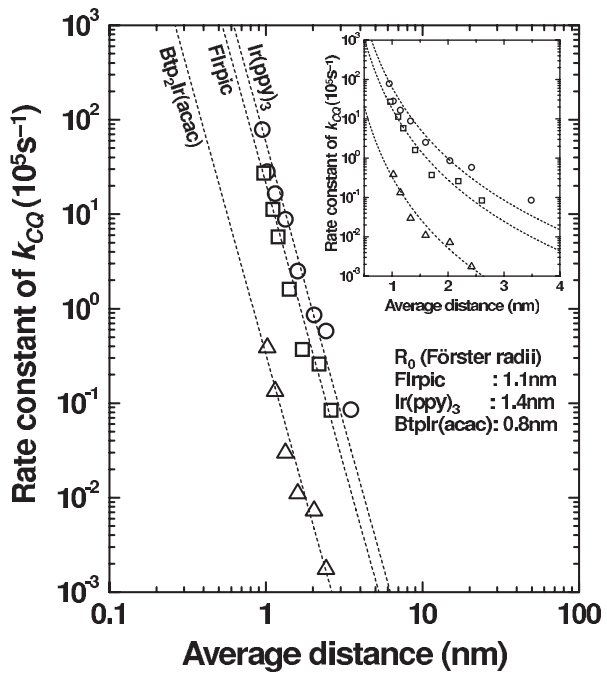

FIG. 2. Dependence of concentration-quenching rate constants $\left(k_{\mathrm{CQ}}\right)$ on average distance $(R)$ plotted by double logarithmic axis for three complexes. The Förster radii $\left(R_{0}\right)$ obtained by fitting the $k_{\mathrm{CQ}}-R$ relations are shown. Inset also shows $R$ vs $k_{\mathrm{CQ}}$ by linear $(R)$-logarithmic $\left(k_{\mathrm{CQ}}\right)$ axes.

where $c$ is the velocity of light, $\chi^{2}$ is the orientation factor (typically assumed to be $2 / 3$ for random orientations expected in amorphous films), $n$ is the refractive index of the medium, $N_{A}$ is Avogadro's number, and $\int f_{D}(\nu) \varepsilon_{A}(\nu) \frac{d \nu}{\nu^{4}}$ is the spectral overlap integral between donor PL, $f_{\mathrm{D}}(\nu)$, and acceptor absorption, $\varepsilon_{A}(\nu)$, when the function $f_{\mathrm{D}}(\nu)$ is normalized as $\int f_{\mathrm{D}}(\nu) d \nu=1$. Figure 3 shows the absorption and PL spectra of the $\operatorname{Ir}(\mathrm{III})$ complexes in a dichloromethane solution $\left(2 \times 10^{-5} \mathrm{M}\right)$. These spectra show how the phosphorescent emission overlaps with the ${ }^{3}$ MLCT absorption bands. Because of the weak oscillator strength of the ${ }^{3}$ MLCT (molar absorption coefficient $<$ $10^{3} \mathrm{M}^{-1} \mathrm{~cm}^{-1}$ ), the overlap integrals of the $\operatorname{Ir}(\mathrm{III}) \mathrm{com}-$ plexes are smaller than that of conventional fluorescence materials. Using Eq. (3), the $R_{0}$ values determined from the solution absorption and emission overlap integral, the quantum efficiency in the doped thin film $\left[\eta_{\mathrm{PL}}=97 \%\right.$ for $\operatorname{Ir}(\mathrm{ppy})_{3}, 99 \%$ for FIrpic, $51 \%$ for $\mathrm{Btp}_{2} \operatorname{Ir}($ acac $\left.)\right]$, and $n=1.7$ were $1.8 \mathrm{~nm}$ for $\operatorname{Ir}(\mathrm{ppy})_{3}, 1.7 \mathrm{~nm}$ for FIrpic, and $1.5 \mathrm{~nm}$ for $\mathrm{Btp}_{2} \operatorname{Ir}(\mathrm{acac})$. The $R_{0}$ values obtained from Eq. (3) are comparable to the values from Eq. (2), and the same ordering of $R_{0}$ is observed in both cases.

It was also considered whether exciton quenching interactions can occur via the Dexter energy transfer mechanism [15]. Based on Dexter theory, $k_{\mathrm{CQ}}$ would be expected to decrease exponentially with $R$. However, as shown in the inset of Fig. 2, a large deviation from exponential dependence is observed, suggesting that the Dexter interaction is not the dominant mechanism for long range exciton quenching, although it would be possible that Dexter quenching also occurs at these distances, as close contact between the phosphors can significantly enhance the Dexter process.

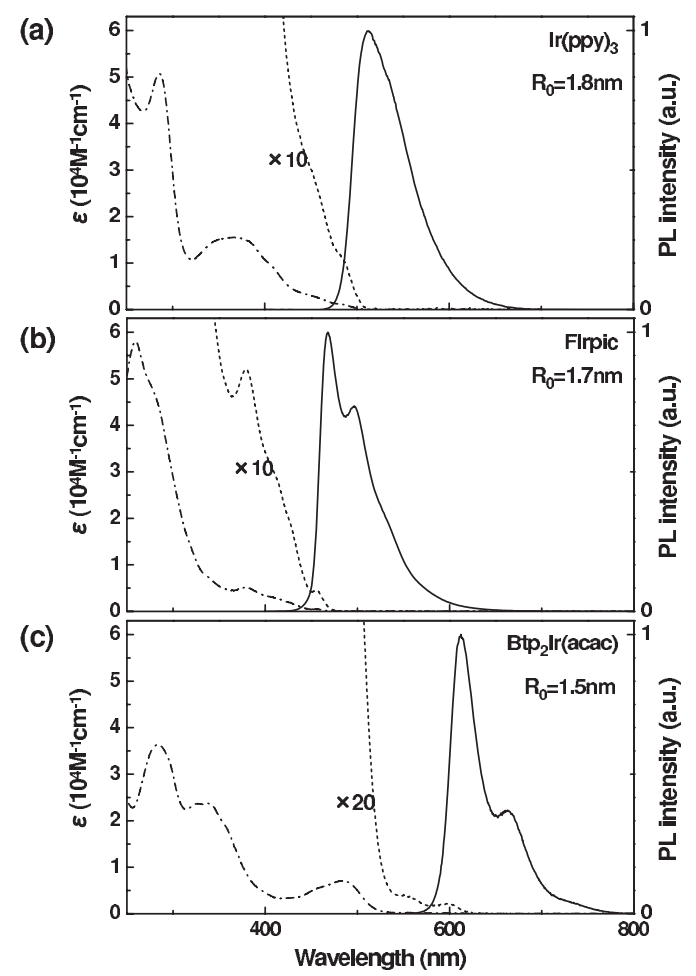

FIG. 3. Absorption (broken line) and PL spectra (solid line) of (a) $\operatorname{Ir}(\mathrm{ppy})_{3}$, (b) FIrpic, and (c) Btp ${ }_{2} \operatorname{Ir}$ (acac) in methylenechloride $\left(2 \times 10^{-5} \mathrm{M}\right)$. The dotted lines show the absorption value expanded 10 times for the $\operatorname{Ir}(\mathrm{ppy})_{3}$ and FIrpic and 20 times for the $\mathrm{Btp}_{2} \operatorname{Ir}(\mathrm{acac})$. The Förster radii $\left(R_{0}\right)$ obtained by the spectral overlap in Eq. (3) are shown.

The excellent agreement with the Förster model strongly suggests that concentration quenching in the phosphorescent Ir(III) complex:host films is governed by dipoledipole interactions. Based on this, it is our understanding that concentration quenching can be ascribed to the dampening of energy through the multiple dipole-dipole energy exchange interactions that readily occur between neighboring Ir molecules [16]. Although $\operatorname{Ir}(\mathrm{ppy})_{3}$ is measured to have a very high $\eta_{\mathrm{PL}}$ of $97 \% \pm 2 \%$ at high dilution in a solid film, a few percent of the excited states are still consumed by nonradiative decay. This dampening effect of the excited state energy can also be described by the classical dipole oscillation model. In this model both near and far electromagnetic fields are simultaneously radiated from an excited molecule. As described by Kuhn, the near field interaction (proximity field to the electric field of the sensitizer) decays according to $R^{-6}$, identical to the Förster expression for radiationless energy transfer [16]. Therefore, it is probable that through the near field energy exchange, i.e., the repeated emission and absorption of light between adjacent Ir molecules, some of the excited states are lost to thermal deactivation. To confirm this consideration, an additional experiment to clarify the deactivation process based on the resonant energy transfer is now in progress. 

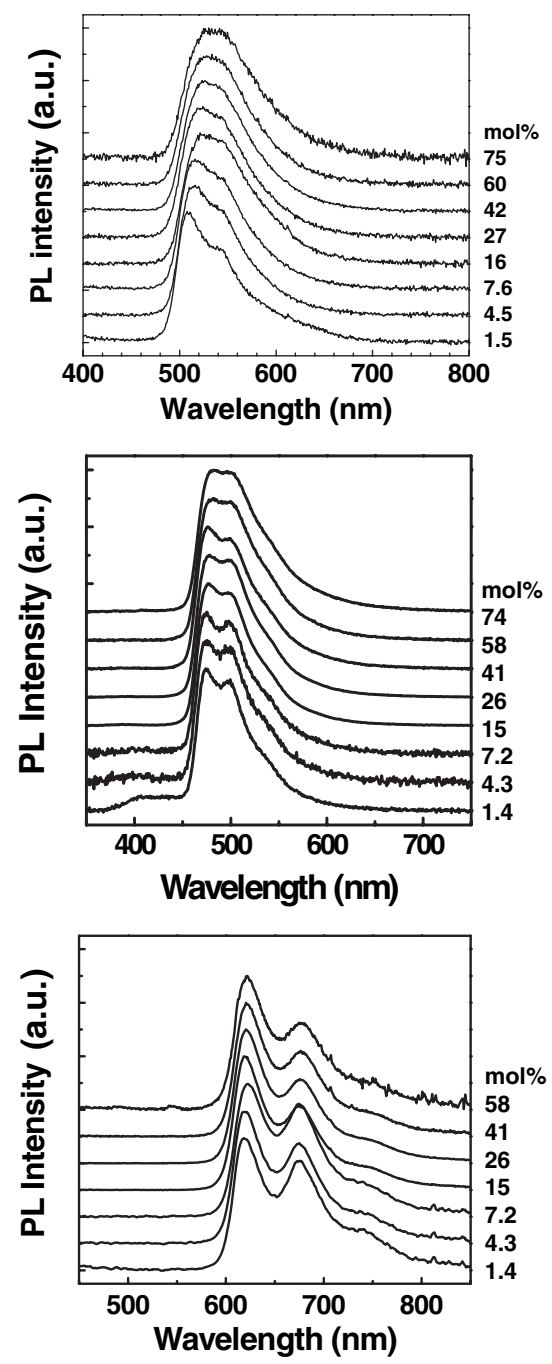

FIG. 4. Concentration dependences of PL spectra of

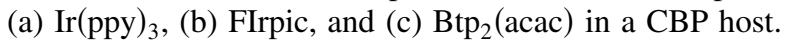

The emissive complexes used in this study have strong heavy atom induced spin-orbital coupling. This effect enhances the formally forbidden singlet-triplet intersystem crossing transition leading to highly efficient phosphorescence with a transient lifetime of a few $\mu$ s. Despite this, the radiative decay rate of $\operatorname{Ir}(\mathrm{ppy})_{3}$, for example, $\left(k_{\mathrm{r}}=8.0 \times\right.$ $10^{5}$ ), is nearly 2 orders of magnitude smaller than that of typical fluorescent laser dyes $\left(k_{\mathrm{r}} \sim 10^{8}\right)$ [12]. Therefore, the oscillator strength for the radiative transition of these organometallic phosphors is significantly less than that of fluorescent materials. This relatively weak oscillator strength leads to a smaller Förster radius of $R_{0}<2 \mathrm{~nm}$ for the Ir complexes compared to an $R_{0} \sim 10 \mathrm{~nm}$ in fluorescent materials.

Finally, we mention the influence of the molecular aggregation of the phosphors with an increase of the dopant concentration. It has been widely known that molecular materials tend to aggregate at their high concentrations and should influence the PL characteristics. Therefore, we carefully measured the PL spectra depending on the concentration as shown in Fig. 4. In these three phosphors, we observed slight broadening of the PL spectra at their higher concentrations in the $\operatorname{Ir}(\mathrm{ppy})_{3}$ and FIrpic, although $\mathrm{Btp}_{2} \operatorname{Ir}(\mathrm{acac})$ showed no appreciable broadening even with the high concentrations. Thus, the presence of molecular aggregation may occur in the $\operatorname{Ir}(\mathrm{ppy})_{3}$ and FIrpic films at their high concentrations, and the aggregated sites would efficiently quench the excited states due to their low PL efficiency. We should incorporate this aggregation effect to correctly describe the concentration-quenching effect. However, the definite $R^{-6}$ dependence observed in the three phosphors supports that our consideration is appropriate and the correction due to the aggregation may be small.

*Electronic address: adachi@cstf.kyushu-u.ac.jp

[1] Y. Kawamura, K. Goushi, J. Brooks, J. J. Brown, H. Sasabe, and C. Adachi, Appl. Phys. Lett. 86, 071104 (2005).

[2] C. Adachi, M. A. Baldo, and S. R. Forrest, J. Appl. Phys. 90, 5048 (2001).

[3] M. Ikai, S. Tokito, Y. Sakamoto, T. Suzuki, and Y. Taga, Appl. Phys. Lett. 79, 156 (2001).

[4] C. Adachi, R. C. Kwong, P. Djurovich, V. Adamovich, M. A. Baldo, M.E. Thompson, and S.R. Forrest, Appl. Phys. Lett. 79, 2082 (2001).

[5] K. Goushi, H. Sasabe, R. C. Kwong, J. J. Brown, and C. Adachi, J. Appl. Phys. 95, 7798 (2004).

[6] K. Goushi, Y. Kawamura, H. Sasabe, and C. Adachi, Jpn. J. Appl. Phys. 43, L937 (2004).

[7] I. Tanaka, Y. Tabata, and S. Tokito, Chem. Phys. Lett. 400, 86 (2004).

[8] E. B. Namdas, A. Ruseckas, I. D. W. Sammuel, S.-C. Lo, and P. L. Burn, J. Phys. Chem. B 108, 1570 (2004).

[9] T. Förster, Discuss. Faraday Soc. 27, 7 (1959).

[10] C. Adachi, M. A. Baldo, S. R. Forrest, S. Lamansky, M. E. Thompson, and R.C. Kwong, Appl. Phys. Lett. 78, 1622 (2001).

[11] R. J. Holmes, S. R. Forrest, Y.-J. Tung, R. C. Kwong, J. J. Brown, S. Garon, and M. E. Thompson, Appl. Phys. Lett. 82, 2422 (2003).

[12] Y. Kawamura, H. Sasabe, and C. Adachi, Jpn. J. Appl. Phys., Part 1 43, 7729 (2004).

[13] K.-C. Tang, K.-L. Liu, and I.-C. Chen, Chem. Phys. Lett. 386, 437 (2004).

[14] K. Goushi, J. J. Brown, and C. Adachi, in Extended Abstracts, the 63rd Autumn Meeting [Jpn. Soc. Appl. Phys. 26p-ZH-10 (2002)].

[15] D. L. Dexter, J. Chem. Phys. 21, 836 (1953).

[16] H. Kuhn, J. Chem. Phys. 53, 101 (1970). 